\title{
Differences in ground motion and fault rupture process between the surface and buried rupture earthquakes
}

\author{
Takao Kagawa $^{1}$, Kojiro Irikura ${ }^{2}$, and Paul G. Somerville ${ }^{3}$ \\ ${ }^{1}$ Geo-Research Institute, 4-3-2 Itachibori, Nishi-ku, Osaka 550-0012, Japan \\ ${ }^{2}$ Disaster Prevention Research Institute, Kyoto University, Japan \\ ${ }^{3}$ URS Corporation, USA
}

(Received July 22, 2003; Revised December 19, 2003; Accepted December 26, 2003)

\begin{abstract}
We have studied differences in ground motion and fault rupture characteristics between surface rupture and buried rupture earthquakes. We found that the ground motion generated by buried rupture in the period range around 1 second is on average 1.5 times larger than the average empirical relationship. In contrast, ground motion from earthquakes that rupture the surface is 1.5 times smaller in the same period range. This phenomenon is considered to be caused by differences in fault rupture process between the two types of earthquakes. To examine possible reasons of the above effect we analyzed source slip distribution data derived from waveform inversions, and divided them into two groups: surface rupture and buried rupture earthquakes. It was found that the large slip areas (asperities) of surface rupture earthquakes are concentrated in the depth range shallower than about $5 \mathrm{~km}$. In contrast, large slip areas of buried rupture earthquakes are spread over the depth deeper than $5 \mathrm{~km}$. We also found that the total rupture area of buried rupture earthquakes is 1.5 times smaller than that of surface rupture earthquakes having the same seismic moment, and that deep asperities have about 3 times larger effective stress drops and 2 times higher slip velocities than shallow asperities. These observations are verified by numerical simulations using stochastic Green's function method.
\end{abstract}

Key words: Strong ground motion, surface rupture fault, buried rupture fault, rupture process, asperity, stress drop, slip velocity.

\section{Introduction}

Empirical attenuation relationships are commonly used to predict earthquake strong ground motions. In the attenuation relationships, the seismic engineering parameters (such as peak acceleration or response spectrum) are related to the source/site parameters (e.g. source magnitude, hypocentral distance and site soil conditions) on an empirical basis. Although such attenuation relations are based on recorded strong motion data, the limited number of model parameters and the simplified functional form of the attenuation relationships does not allow it to achieve high prediction accuracy. Recent seismological development have lead to new prediction techniques, that are based on wave propagation calculations using detailed velocity structure including the site, and on the asperity model of the seismic source.

To employ the asperity source model for the prediction of strong ground motions, the characterized asperity model was introduced (e.g. Somerville et al., 1999; Miyakoshi et al., 2000). In this model, the complex slip distribution of a real earthquake is represented by a few rectangular asperities with uniform slip distribution embedded in a fault plane having lower background slip. Based on the analysis of many source slip inversion results of crustal earthquakes, Somerville et al. (1999) introduced scaling relationships for

Copy right (C) The Society of Geomagnetism and Earth, Planetary and Space Sciences (SGEPSS); The Seismological Society of Japan; The Volcanological Society of Japan; The Geodetic Society of Japan; The Japanese Society for Planetary Sciences; TERRAPUB. parameters of the characterized asperity model. Irikura et al. (2001) proposed a recipe for the prediction of strong ground motions from future earthquakes that is based on the characterized asperity model and on the scaling relations adapted to Japan. The main scaling parameter is the seismic moment $M_{0}$.

In this work we introduce more detailed aspects of the earthquake source by considering differences in source characteristics and ground motion characteristics between surface rupture and buried rupture crustal earthquakes. Here we define a surface rupture earthquake as an earthquake which has clear surface dislocation caused by the earthquake, and significant slip at shallow depth (shallower than $5 \mathrm{~km}$ ), as inferred from slip model inversion. On the other hand, we define a buried rupture earthquake as an earthquake that does not have clear surface dislocation and shallow slip. Preliminary analysis of Somerville (2003) shows that the ground motions of the buried ruptures are stronger than the ground motions of surface ruptures in the period $\operatorname{range}$ around $T=1$ sec. The importance of this observation is enhanced by the fact that some buried rupture earthquakes occur on buried faults which have no surface trace and whose locations are unknown in some cases.

We first compare the observed ground motions for surface ruptures and buried ruptures, following to Somerville (2003). Then, we analyze the depth distribution of the asperities of the available slip models, and re-estimate the asperity locations based on the original slip distribution data and on 


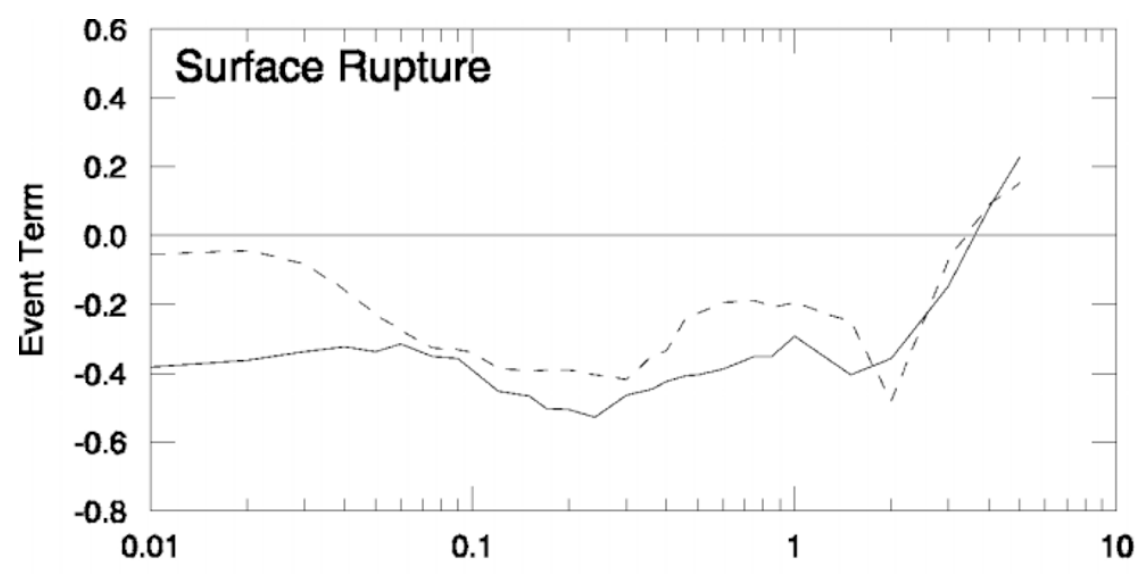

Chi-Chi, Taiwan 7.6

Izmit, Turkey 7.4

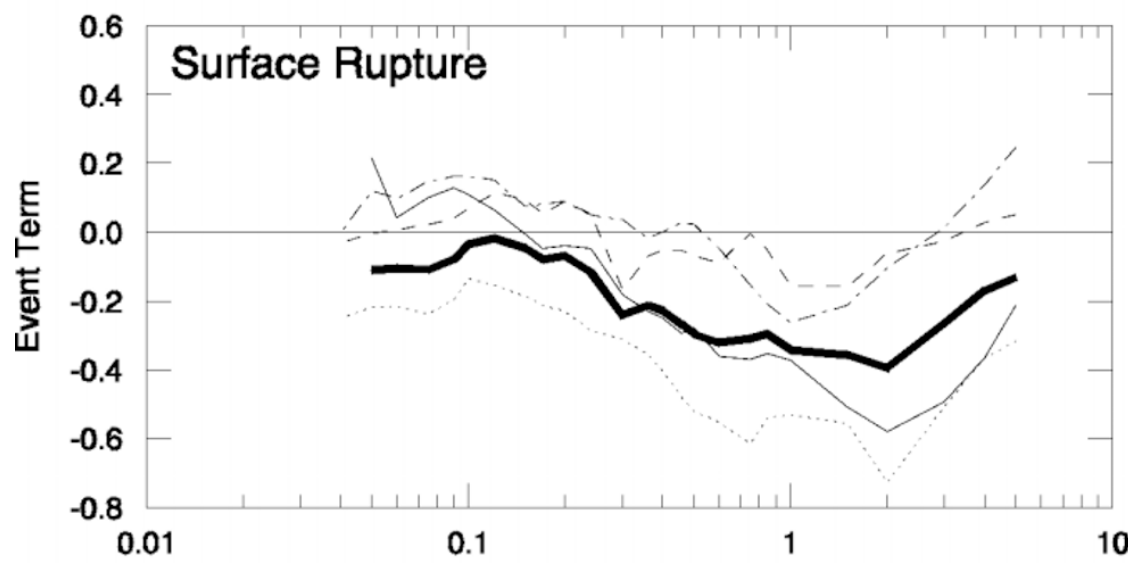

Landers 7.2

Tabas 7.1

San Fernando 6.6

Imperial Valley 6.5

Average of 6 Surface

Rupture Events

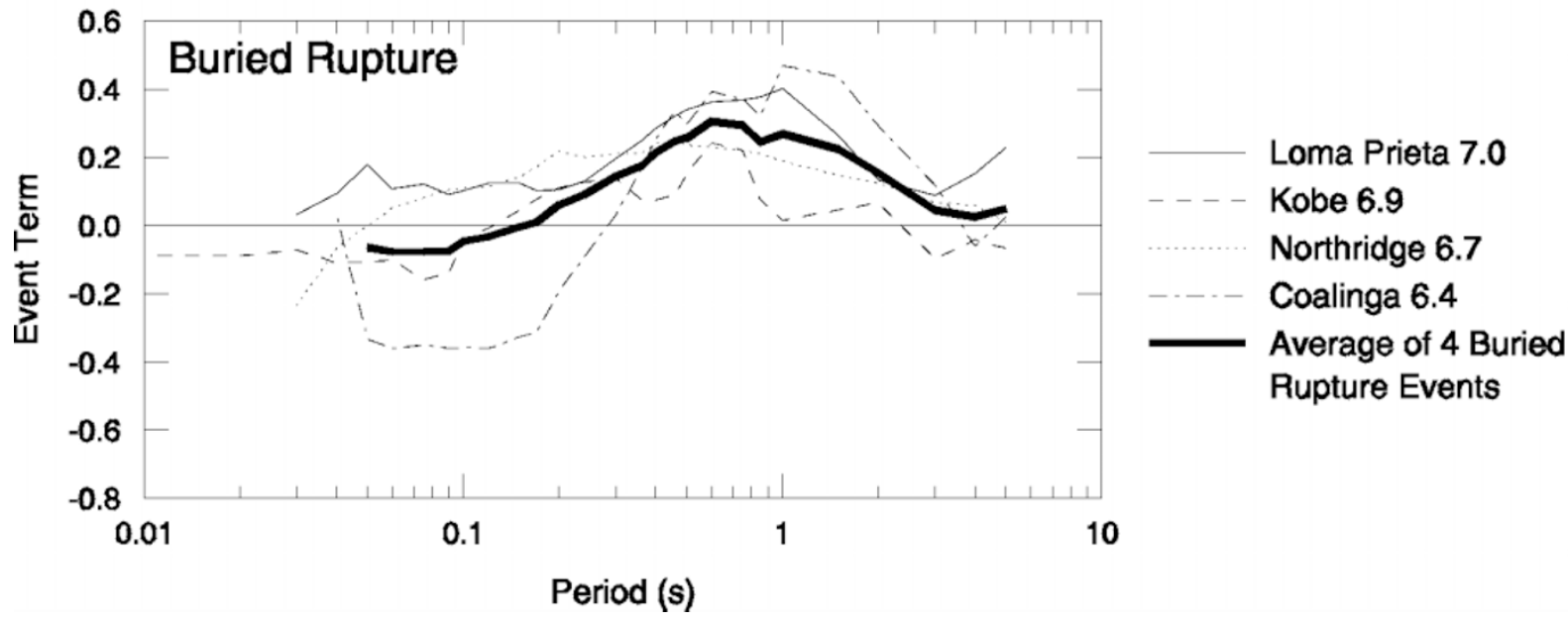

Fig. 1. Ratio of response spectra of recorded ground motions to that of an empirical attenuation relationship for the cases of surface rupture earthquake (top and center) and buried rupture earthquake (bottom). The zero line represents the level of the empirical attenuation relationship. Lines above the zero line indicate an event's ground motion exceeding the model.

the results of analysis of the distribution of asperities with depth. Finally, separate scaling relationships are derived for surface ruptures and buried ruptures. These results are verified by numerical simulations using the stochastic Green function method.
2. Observed Difference in Ground Motions between Buried and Surface Rupture Earthquakes Somerville (2003) has indicated that the ground motion generated by buried rupture in the period range around 1 second is larger than the ground motion from earthquakes with surface rupture. This phenomenon is demonstrated in Fig. 1, which shows data separately for surface rupture earthquakes (top and center) and for buried rupture earthquakes 
Table 1. Numbers of rock and soil sites of the records used in the Fig. 1. Italic fonts indicate earthquakes that are not used in the empirical relationship by Abrahamson and Silva (1997).

\begin{tabular}{|c|c|c|c|c|}
\hline \multicolumn{2}{|c|}{ Ear thquake Types } & Ear thquakes & Rock Sites & Soil Sites \\
\hline \multirow{6}{*}{ Surface } & \multirow{2}{*}{ large } & Ghichi, Taiwan, 1999 & 13 & 15 \\
\hline & & Kocaeli, Turkey, 1999 & 26 & 7 \\
\hline & \multirow{4}{*}{ middle } & Landers, 1992 & 10 & 45 \\
\hline & & Tabas, Iran, 1978 & 1 & 1 \\
\hline & & San Fernando, 1971 & 23 & 32 \\
\hline & & Imperial Valley, 1979 & 2 & 33 \\
\hline \multirow{4}{*}{ Bur ied } & \multirow{4}{*}{ middle } & Loma Prieta, 1989 & 31 & 29 \\
\hline & & Kobe, Japan, 1995 & 1 & 12 \\
\hline & & Northridge, 1994 & 18 & 33 \\
\hline & & Coal inga, 1983 & 20 & 28 \\
\hline
\end{tabular}

(bottom). The plots indicate residuals between the ground motions of selected individual earthquakes and the empirical ground motion attenuation relationship of Abrahamson and Silva (1997), i.e. event term, versus period. The zero line represents the model of Abrahamson and Silva (1997) that takes into account the magnitude, distance, and site conditions. Lines above the zero line indicate an event whose ground motion exceeds the model level. Here, 0.4 natural $\log$ units equals a factor of nearly 1.5. Some of the earthquakes treated in the Fig. 1 occurred after 1997, so the event terms were not calculated by Abrahamson and Silva (1997). For these earthquakes, we use the residuals between the data and the model to represent the event term.

In the period range around 1 second (say $T=0.5-3.0 \mathrm{sec}$ ), the ground motions from magnitude $M_{W}=6.5-7.0$ earthquakes without surface rupture (bottom panel) are clearly larger than the average level ( $\sim 1.5$ times). In the period range $T=0.3-3.0 \mathrm{sec}$, the ground motions from the earthquakes with similar magnitude, that produced large tectonic surface rupture, are significantly weaker $(\sim 1.5$ times $)$ even though rupture occurred at the surface (center). We categorize the 1995 Kobe earthquake as a buried rupture earthquake because the strong ground motions observed in the Kobe City area are affected by the north-east portion of the fault which does not have surface break. Similar trends are present for the 1999 Kocaeli, Turkey and 1999 ChiChi, Taiwan earthquakes (top), which have larger magnitude $M_{W}>7.0$. Because the ground motions are averaged over many records at various site conditions for each earthquake, the event terms pertain to the effects of the earthquake source. Table 1 shows the numbers of rock and soil sites of the records used in the Fig. 1. From the table, it appears that the Kocaeli, Kobe and Imperial Valley event terms might be biased by site condition effects, but the event terms for the other earthquakes are not likely to be biased.

We conclude that the ground motion generated by buried rupture earthquakes is larger than the ground motion generated by surface rupture earthquakes. This phenomenon is considered to be caused by differences in the fault rupture process between these two types of earthquakes. In this paper we study differences in rupture parameters, namely: rupture area, asperity area, asperity depth, stress drop of the fault, stress drop of the asperities, and slip velocity.

\section{Depth Distribution of Asperities}

Somerville et al. (1999) analyzed the slip distributions of 15 crustal earthquakes derived by waveform inversion mainly from strong ground motion data. The slip models that we used were developed using a fairly uniform procedure, mostly by the technique proposed by Hartzell and Heaton (1983). The resolution of shallow slip is important for this study. Strong ground motions are sensitive to shallow slip, because shallow slip causes large surface waves. For this reason, we expect that the resolution of shallow slip should be quite good. For example, Wald and Heaton (1994) analyzed the 1992 Landers earthquake using geodetic data, strong ground motion data, teleseismic data, and combined data. The slip model obtained using strong ground motion data alone yielded a distribution of surface slip that is similar to that obtained by the other data sets, and to the observed slip distribution.

Somerville et al. (1999) converted the inversion results in a consistent way into characterized source models with rectangular asperities. In this work we have used those results in several ways, first to analyze the depth distribution of asperities. Figure 2 shows the depth distribution of the probabilistic density function of asperity location. The top plot is for all 15 earthquakes with 39 asperities, the center panel is for surface rupture earthquakes ( 8 earthquakes, 22 asperities) and the bottom panel is for buried rupture earthquakes (7 earthquakes, 17 asperities). To divide the earthquakes into these two groups, we used the results of Wells and Coppersmith (1994) who reanalyzed original field observation data and identified whether the surface was ruptured or not. Earthquakes that occurred in 1994 and later that were not included in the work of Wells and Coppersmith (1994), were analyzed 

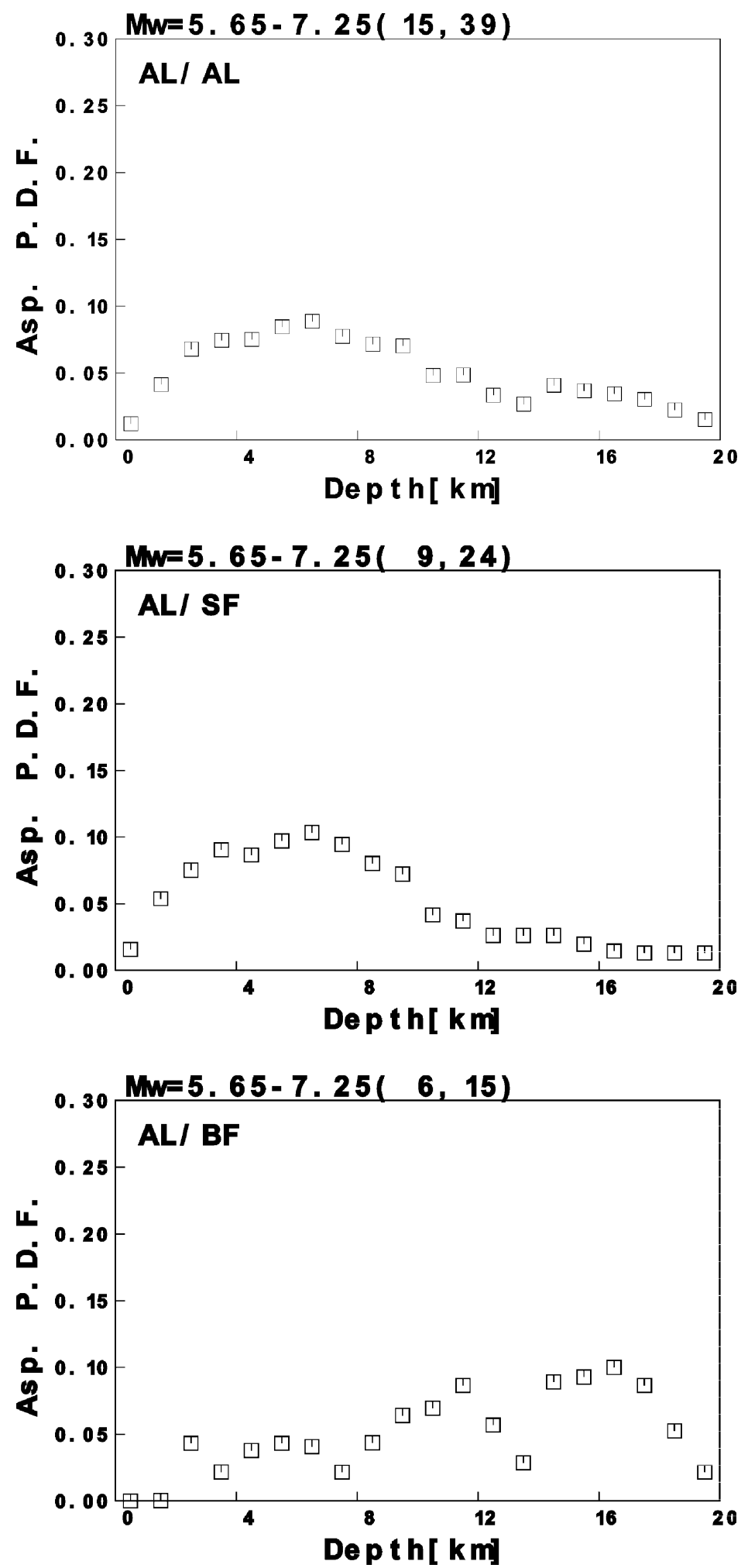

Fig. 2. Depth distribution of the probability density function of asperity location according to the data of Somerville et al. (1999). The top, center, and bottom panels show the cases of all earthquakes, surface rupture earthquakes, and buried rupture earthquakes respectively.

separately in this work, based on the original field data.

Figure 2 clearly demonstrates that asperities of surface rupture earthquakes are concentrated in the shallow depth range between 2 and $10 \mathrm{~km}$, and asperities of buried rupture earthquakes are distributed almost uniformly with depth in the upper crust at depths greater than $5 \mathrm{~km}$.

\section{Identification of Shallow and Deep Asperities}

To construct new source parameter scaling relations, similar to those of Somerville et al. (1999) allowing for the differences between shallow and deep events discussed above, we reanalyzed the original source slip distribution data used by Somerville et al. (1999) as well as the newly derived source models of several recent earthquakes. These in- 
Table 2. Fault parameters of the analyzed earthquakes.

\begin{tabular}{|c|c|c|c|c|c|c|c|c|c|}
\hline Earthquakes & $\mathrm{M}_{\mathrm{W}}$ & $\begin{array}{c}\text { Rupture } \\
\text { Area } \\
\left(\mathrm{km}^{2}\right)^{*}\end{array}$ & $\begin{array}{c}\text { Depth of } \\
\text { Fault Top } \\
(\mathrm{km})\end{array}$ & $\begin{array}{c}\text { Dip Angle } \\
(\mathrm{degree})\end{array}$ & $\begin{array}{c}\text { Seismic } \\
\text { Moment } \\
(\mathrm{Nm})^{*}\end{array}$ & $\begin{array}{c}\text { Effective } \\
\text { Stress } \\
(\mathrm{MPa})\end{array}$ & $\begin{array}{c}\text { Average } \\
\text { Slip }(\mathrm{cm})\end{array}$ & $\begin{array}{c}\text { Surface } \\
\text { Break }\end{array}$ & $\begin{array}{c}\text { Shallow } \\
\text { Asperities }\end{array}$ \\
\hline Borah Peak, 1983 & 6.8 & 1287 & 1.0 & 49 & $1.92 \times 10^{19}$ & 1.0 & 47 & YES & YES \\
\hline ChiChi, Taiwan, 1999 & 7.5 & 3200 & 0.1 & 29 & $1.93 \times 10^{20}$ & 2.6 & 245 & YES & YES \\
\hline Coyote Lake, 1979 & 5.8 & 30 & 3.5 & 80 & $6.02 \times 10^{17}$ & 9.0 & 67 & NO & NO \\
\hline Imperial Valley, 1979 & 6.3 & 360 & 0.0 & 90 & $3.47 \times 10^{18}$ & 1.2 & 69 & YES & NO \\
\hline Iwate, Japan, 1998 & 5.7 & 120 & 5.0 & 41 & $4.95 \times 10^{17}$ & 0.9 & 14 & NO \\
\hline Kagoshima, Japan, 1997 & 5.9 & 144 & 0.7 & 79 & $1.05 \times 10^{18}$ & 1.5 & 25 & NO & NO \\
\hline Kobe, Japan, 1995 & 6.8 & 1200 & 0.2 & 83 & $2.13 \times 10^{19}$ & 1.3 & 67 & YES & YES \\
\hline Kocaeli, Turkey, 1999 & 7.4 & 3243 & 0.0 & 90 & $1.42 \times 10^{20}$ & 1.9 & 141 & YES & YES \\
\hline Landers, 1992 & 7.2 & 1035 & 0.1 & 90 & $7.48 \times 10^{19}$ & 5.5 & 269 & YES & YES \\
\hline Loma Prieta, 1989 & 7.0 & 720 & 3.4 & 70 & $3.99 \times 10^{19}$ & 5.0 & 166 & NO & NO \\
\hline Morgan Hill, 1984 & 6.0 & 299 & 0.5 & 90 & $1.10 \times 10^{18}$ & 0.5 & 17 & NO & YES \\
\hline Nagano, Japan, 1984 & 6.0 & 91 & 0.3 & 74 & $1.43 \times 10^{18}$ & 4.0 & 57 & NO & YES \\
\hline Nahanni, Canada, 1985.12 & 6.7 & 616 & 2.0 & 25 & $1.41 \times 10^{19}$ & 2.2 & 76 & NO & YES \\
\hline Nahanni, Canada, 1985.10 & 6.6 & 408 & 0.2 & 35 & $8.88 \times 10^{18}$ & 2.6 & 86 & NO & YES \\
\hline North Palm Springs, 1986 & 6.1 & 266 & 4.0 & 46 & $1.87 \times 10^{18}$ & 1.1 & 17 & NO & NO \\
\hline Northridge, 1994 & 6.7 & 351 & 5.0 & 40 & $1.32 \times 10^{19}$ & 4.9 & 103 & & NO \\
\hline Superstition Hills, 1987 & 6.5 & 161 & 4.0 & 90 & $6.23 \times 10^{18}$ & 7.4 & 78 & YES & NO \\
\hline Tabas, Iran, 1978 & 7.0 & 4275 & 1.0 & 25 & $3.69 \times 10^{19}$ & 0.3 & 50 & YES & YES \\
\hline Tottori, Japan, 2000 & 6.7 & 567 & 0.0 & 90 & $1.63 \times 10^{19}$ & 2.9 & 91 & YES \\
\hline Whittier Narrows, 1987 & 5.9 & 100 & 12.1 & 30 & $7.72 \times 10^{17}$ & 1.9 & 26 & NO & NO \\
\hline
\end{tabular}

$*$ : Estimated from Characteristic Fault Model
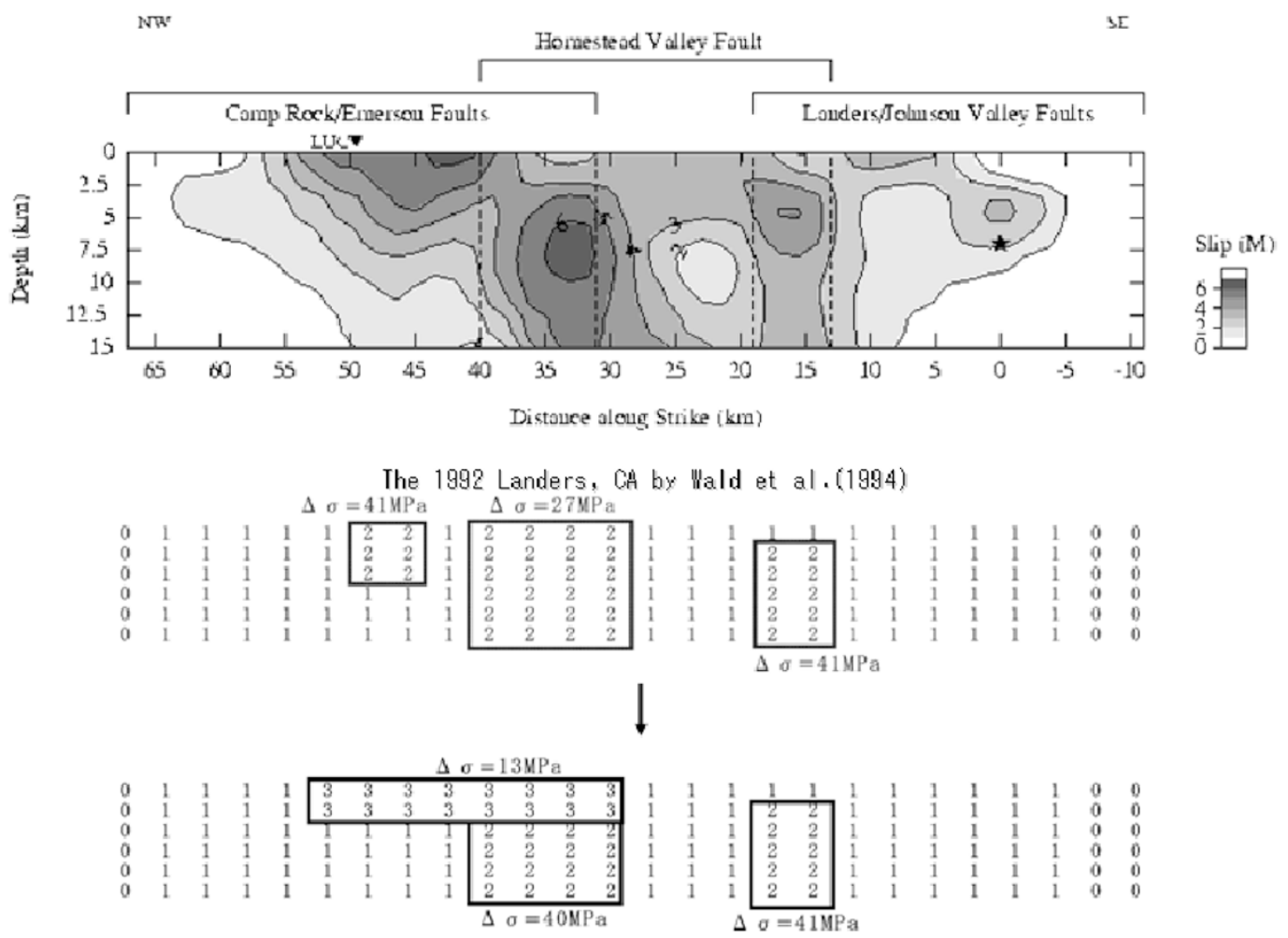

Fig. 3. An example of the asperity identification procedure. The top panel shows the slip distribution in the 1992 Landers Earthquake (Wald and Heaton, 1994). The center and bottom panels show asperities identified without and with partition into shallow and deep asperities respectively.

clude the 1984 Nagano (Yoshida and Koketsu, 1990), 1997 Kagoshima, 1997 Yamaguchi and 1998 Iwate (Miyakoshi et al., 2000) and 2000 Tottori (Sekiguchi and Iwata, 2001) earthquakes in Japan, the 1999 Kocaeli earthquake in Turkey (Sekiguchi and Iwata, 2002) and 1999 ChiChi earthquake, Taiwan (Iwata et al., 2000). Except for the 1984 Nagano earthquake, the slip models were derived using the same in- version technique (Hartzell and Heaton, 1983). Then we divided them into two groups: pure surface rupture and pure buried rupture earthquakes. Table 2 shows the estimated source parameters of the earthquakes analyzed in this paper.

An example of the applied procedure is shown in Fig. 3. The top panel of Fig. 3 shows the original slip distribution of the 1992 Landers earthquake derived by Wald and Heaton 


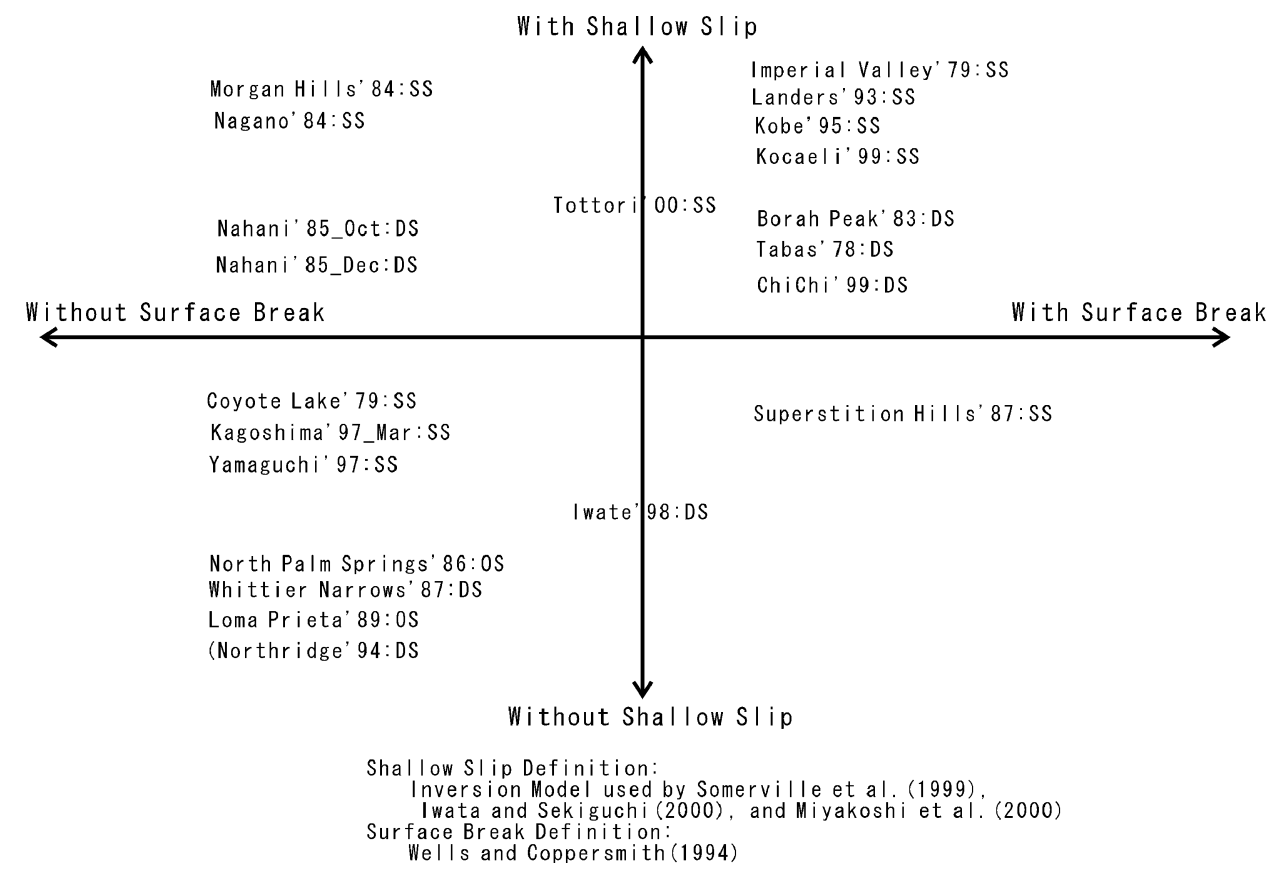

Fig. 4. Categorization of the considered earthquakes into four groups. The horizontal line separates earthquakes with and without shallow asperities, and vertical line separates earthquakes with and without surface breaks.

(1994). An elongated zone of large shallow slip is present just beneath the surface break. The center panel of the figure shows the result of characterizing slip model using the methodology of Somerville et al. (1999). This process incorporated part of the shallow large slip zone into a deep asperity. We used an automated computer-based procedure to identify asperities, following the criteria of Somerville et al. (1999), p. 64

Next, we identified shallow asperities and deep asperities. We first identified asperities from the slip distribution shallower than $5 \mathrm{~km}$ and then we identified deeper asperities from the remaining portion of the fault. We defined the critical depth $h_{c}=5 \mathrm{~km}$ as the best value using a grid search in the depth range $h=3-8 \mathrm{~km}$, by analyzing the fault rupture models of all earthquakes. The bottom panel of Fig. 3 shows the asperities identified in this manner. The effective stress drops are also indicated in the figure. They were estimated assuming a circular crack model (Eshelby, 1957) for the deep asperities (Eq. (1)) where $M_{0}$ and $S$ indicate seismic moment and area of an asperity. A semi-ellipsoid crack model (Watanabe et al., 1998) was applied for the shallow open asperity (Eq. (2)) where the aspect ratio (length $(L)$ over width $(W)$ ) is assumed to be two and Poisson's ratio (v) is assumed to be 0.25 .

$$
\begin{aligned}
& \Delta \sigma_{d}=\frac{7 \pi^{\frac{3}{2}}}{16} \times \frac{M_{0}}{S^{\frac{3}{2}}} \cong 2.436 \times \frac{M_{0}}{S^{\frac{3}{2}}} \\
& \Delta \sigma_{s}=\frac{3 \pi^{\frac{3}{2}}}{8} \frac{2-v}{1-v} \times \frac{M_{0}}{L^{3}} \cong 1.723 \times \frac{M_{0}}{S^{\frac{3}{2}}}
\end{aligned}
$$

Shallow asperities have smaller effective stress than deeper asperities.

Applying the above analysis to all earthquakes, we obtained two groups of earthquakes: those with shallow asperities and those without shallow asperities. Then, by di- viding the earthquakes into events with surface rupture and without surface rupture following Wells and Coppersmith (1994), we divided all the treated earthquakes into the four groups shown in Fig. 4. In this figure, the upper portion contains earthquakes with shallow asperities and the lower half shows those without shallow asperities. Also, the right portion indicates earthquakes with surface breaks and the left portion indicates earthquakes without surface breaks. The events in the upper right quadrant are defined as pure surface rupture earthquakes and those in the lower left quadrant are defined as pure buried rupture earthquakes. Here the 1995 Kobe earthquake is categorized as a surface rupture earthquake because it has clear surface break and shallow asperity, although they did not affect the strong ground motion observed in the Kobe City area as mentioned before. We used the data of these two groups for further analysis.

\section{Scaling Relationships of Surface and Buried Rupture Earthquakes}

Here we analyzed scaling characteristics of both types of earthquakes. First, we analyzed the macroscopic fault rupture parameters, i.e. the total rupture area $A_{0}$, the stress drop $\Delta \sigma_{0}$ and the ratio of the combined asperity area to the fault area $A_{a} / A_{0}$. Figure 5 and Table 3 show the resulting scaling relationships between these parameters and the seismic moment $M_{0}$. Here we used the scale invariant, selfsimilarity assumption, i.e. $A_{0} \sim M_{0}^{2 / 3}, \Delta \sigma_{0}=$ const and $A_{a} / A_{0}=$ const

The relationship for total rupture area $A_{0}$, average over all events, is almost the same as in Somerville et al. (1999). However, separation of the earthquakes into the two groups shows that, on average for the same magnitude, the fault area of buried rupture events is about 1.5 times smaller than that of surface rupture events. Common logarithmic standard deviations from the averages are indicated in the table. This 

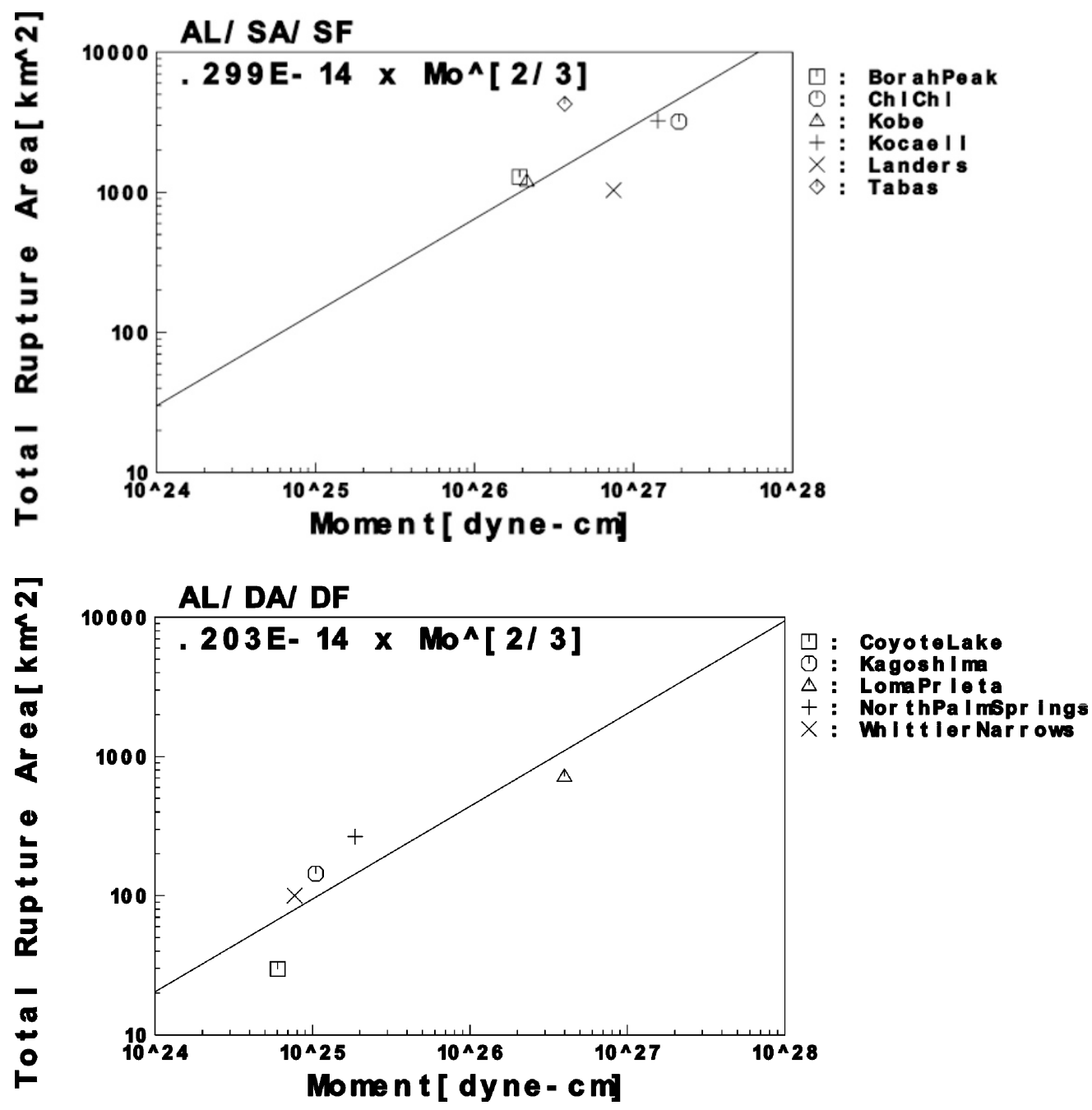

Fig. 5. Scaling relationship between fault rupture area and seismic moment. The self-similar least squares fit lines for surface rupture (upper panel) and for buried rupture (lower panel) are indicated.

Table 3. Scaling relations for the whole ruptures: rupture area $A_{0}$ versus $M_{0}$, stress drop $\Delta \sigma_{0}$, and the ratio of the combined asperity area to the fault area $A_{a} / A_{0}$.

\begin{tabular}{|c|c|c|c|}
\hline & $\begin{array}{c}\text { Mo Vs. Rupture Area } \\
\text { (common logar ithmic } \\
\text { standard deviation) }\end{array}$ & Stress Drop & $\begin{array}{c}\text { Area of Fault } \\
\text { Covered by } \\
\text { Asperities }\end{array}$ \\
\hline All Faults & $2.40 \times 10^{-15} \mathrm{Mo}^{2 / 3} \quad(0.25)$ & $2.9 \pm 2.3 \mathrm{MPa}$ & $0.22 \pm 0.07$ \\
\hline $\begin{array}{c}\text { Faults with Surface Break } \\
\text { and Shal low Asperities }\end{array}$ & $2.97 \times 10^{-15} \mathrm{Mo}^{2 / 3} \quad(0.25)$ & $2.1 \pm 1.7 \mathrm{MPa}$ & $0.22 \pm 0.07$ \\
\hline $\begin{array}{c}\text { Faults without Surface } \\
\text { Break and Shal low } \\
\text { Asperities }\end{array}$ & $2.03 \times 10^{-15} \mathrm{Mo}^{2 / 3} \quad(0.23)$ & $3.7 \pm 3.0 \mathrm{MPa}$ & $0.20 \pm 0.08$ \\
\hline
\end{tabular}

ratio is almost same as the standard error of each scaling relationship, indicating the difference is significant despite the small number of analyzed earthquakes. The average effective $\Delta \sigma$ value for buried rupture earthquakes is almost 2 times larger than that for earthquakes with surface rupture. Standard deviations from the averages are shown in the table. The standard deviations are not small enough, however, the difference of the average values between the two types of earthquake is significant enough. The ratios of the asperity area to the fault area $A_{a} / A_{0}$ are practically the same for these two cases. Standard deviations of the values are also indicated in the table.

Next, we analyzed the characteristics of the individual asperities: effective stress drop of the asperity $\Delta \sigma_{a}$, asperity slip contrast $D_{a} / D_{0}$ (ratio of the asperity slip $D_{a}$ to the average slip $D_{0}$ ) and the effective slip velocity $V_{\text {eff }}$. Again, the self-similarity assumption was employed, i.e. $\Delta \sigma_{a}=$ const, $V_{\text {eff }}=$ const and $D_{a} / D_{0}=$ const . 

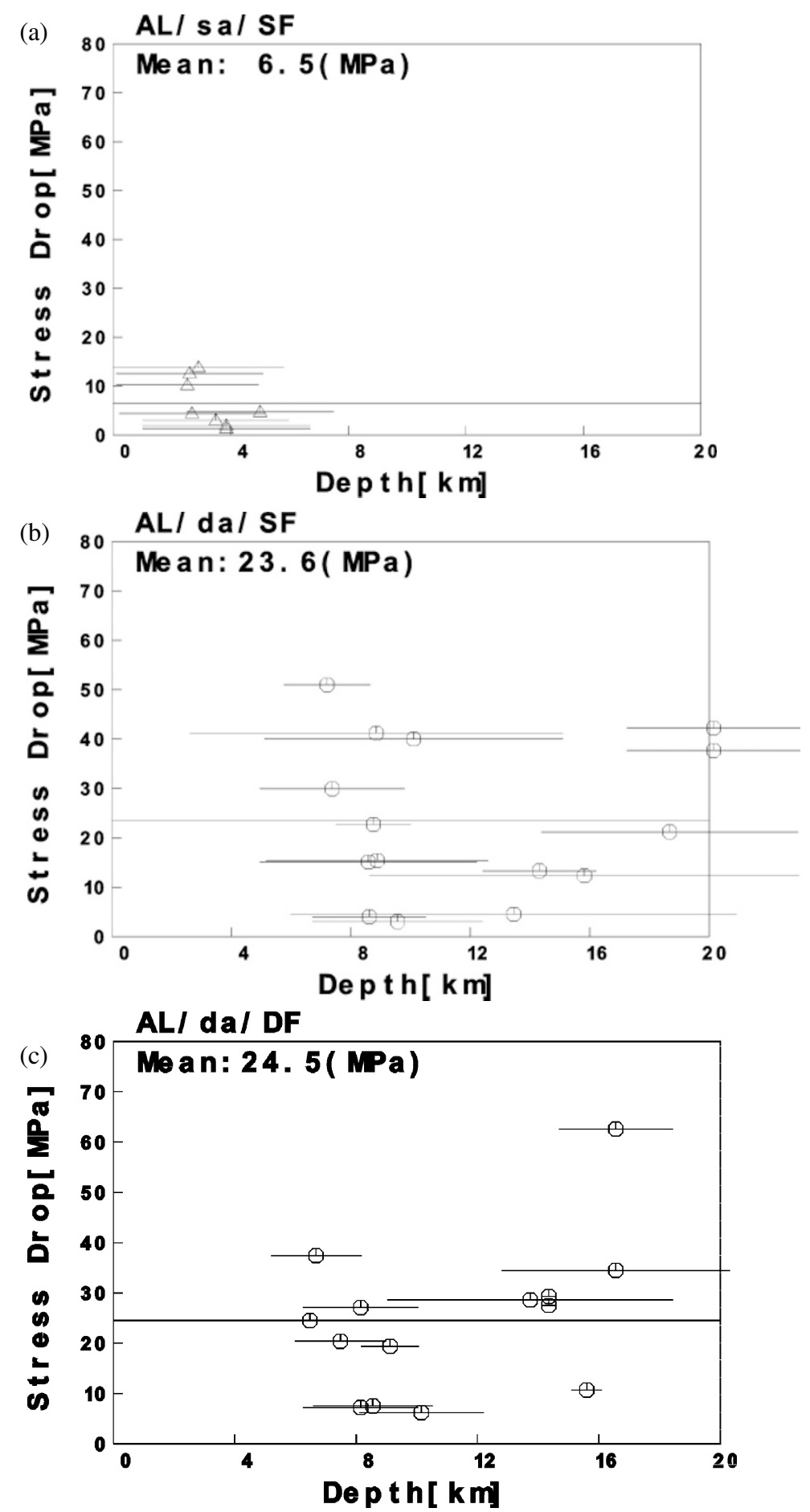

Fig. 6. Depth distribution of effective stress drops estimated for asperities. Asperities (from top to bottom) are indicated by horizontal lines, and circle marks are the centroids of each asperity. (a) Shallow asperities of surface rupture earthquakes. (b) Deep asperities of surface rupture earthquakes. (c) Deep asperities of buried rupture earthquakes.

Figure 6 and Table 4 show the depth distribution of $\Delta \sigma_{a}$. From the figure, we can clearly see that the $\Delta \sigma_{a}$ values of the shallow asperities are much smaller ( $\sim 3$ times) than those of the deep asperities. Deep asperities both on surface rupture faults and on buried rupture faults have almost the same stress drop, $\Delta \sigma_{a}=23.6 \pm 15.2 \mathrm{MPa}$ and $\Delta \sigma_{a}=24.5 \pm$ 14.5 MPa respectively. Standard deviations are evaluated similarly as Table 3 . The values of the effective stress drops of shallow and deep asperities seem to have large scatter when the values from all of the earthquakes are combined. However, the ratio of stress drops between shallow and deep asperities of each earthquake has less scatter, and is a factor of about three. The scatter in the effective stress drops of asperities is considered to be caused by the distribution of average stress drops of the individual earthquakes shown in Table 3.

Figure 7 shows the depth distribution of the slip velocities $V_{\text {eff }}$ for the same asperity data. Again, slip velocities on the 
Table 4. Scaling parameters (the const values) for individual asperities: effective stress drops $\Delta \sigma_{a}$, asperity slip contrast $D_{a} / D_{0}$ and slip velocity $V_{e f f}$.

\begin{tabular}{|c|c|c|c|c|}
\hline \multicolumn{2}{|c|}{} & Stress Drop & $\begin{array}{c}\text { Asperity SI ip } \\
\text { Contrast }\end{array}$ & $\begin{array}{c}\text { Effective SIip } \\
\text { Velocity }\end{array}$ \\
\hline $\begin{array}{c}\text { Surface } \\
\text { Break } \\
\text { Fault }\end{array}$ & Shal low Asperities & $6.5 \pm 4.6 \mathrm{MPa}$ & $2.1 \pm 0.4$ & $133 \pm 60 \mathrm{~cm} / \mathrm{s}$ \\
\cline { 2 - 4 } & Deep Asperities & $23.6 \pm 15.2 \mathrm{MPa}$ & $2.0 \pm 0.3$ & \multirow{2}{*}{$286 \pm 164 \mathrm{~cm} / \mathrm{s}$} \\
\hline $\begin{array}{c}\text { Buried } \\
\text { Fault }\end{array}$ & Deep Asperities & $24.5 \pm 14.5 \mathrm{MPa}$ & $2.4 \pm 0.8$ & \\
\hline
\end{tabular}

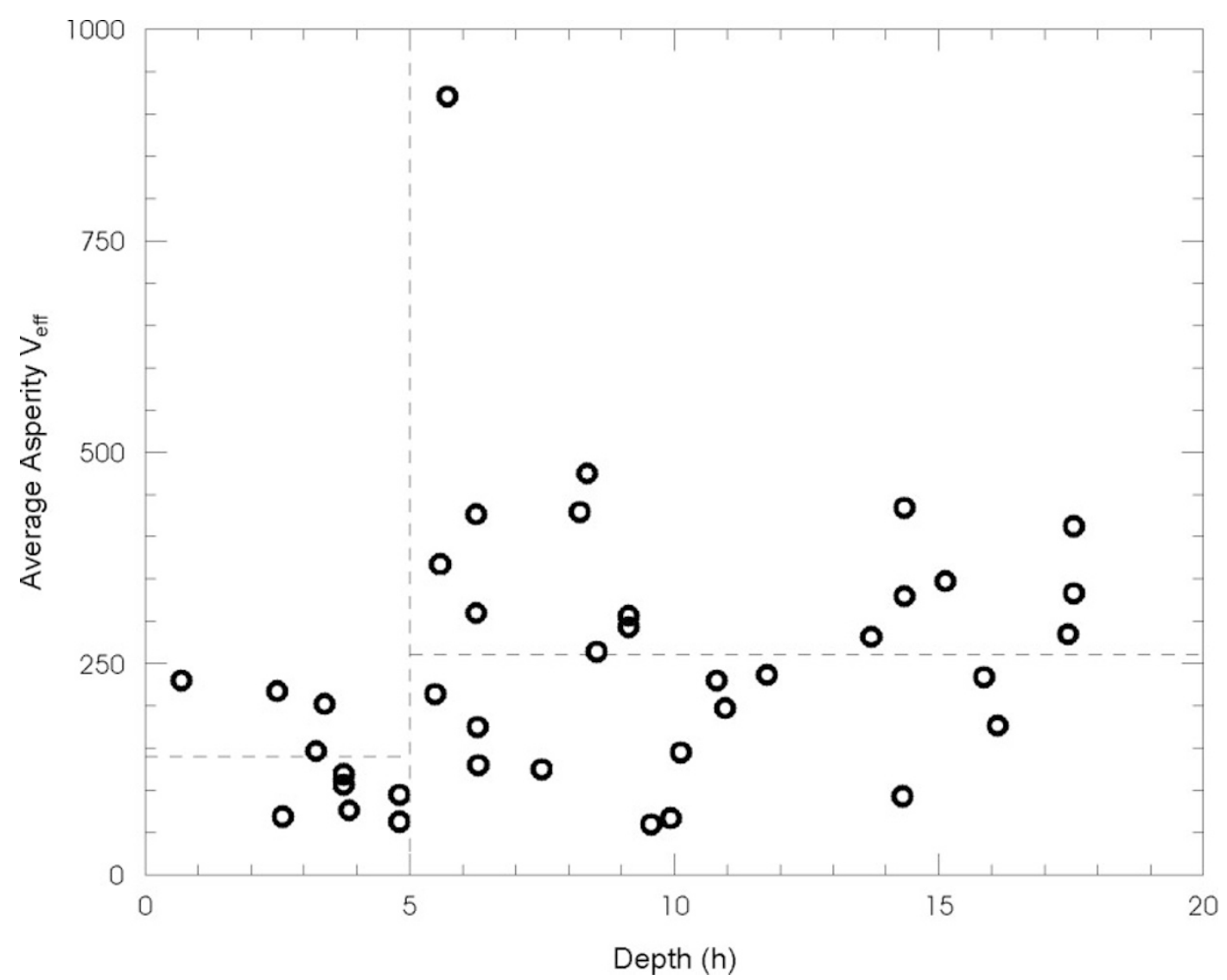

Fig. 7. Depth distribution of slip velocity for all asperities. Indicated depths are the centroids of the asperities.

deep asperities are about twice those of the shallow asperities: $133 \pm 60 \mathrm{~cm} / \mathrm{s}$ and $286 \pm 164 \mathrm{~cm} / \mathrm{s}$ respectively. The outlier in Fig. 7, from the 1985 Oct. Nahanni earthquake, makes the standard deviation large. Values of the asperity slip contrast $D_{a} / D_{0}$ in Table 4 are practically the same for the shallow and deep asperities.

We consider the significant differences of effective stress drop and slip velocity between shallow and deep asperities reflect the depth dependency of these values in the crustal layer. However, the depth dependency is not gradual but abrupt at a depth around $5 \mathrm{~km}$. This critical depth might have local and regional variations.

\section{Simulation of Strong Ground Motions of Shal- low and Buried Earthquakes}

To test whether the derived differences in the source characteristics can explain the observed differences in the ground motions between the two types of earthquakes, we constructed examples of the characterized fault rupture models for surface and buried rupture earthquakes, and calculated the strong ground motion records in the near fault region by the stochastic Green's function method (Boore, 1983; Kamae and Irikura, 1992).

Figure 8 shows the characterized rupture models used in the calculations. We assumed the seismic moment of the earthquakes to be $M_{0}=7.5 \times 10^{18} \mathrm{Nm}\left(M_{W}=6.5\right)$, corresponding to the maximum magnitude for buried rupture crustal earthquakes proposed by Shimazaki (1986). The fault and the asperity areas were estimated from the scaling relationships in Table 3. We assumed a two-asperity model. The larger asperity has an area of about $16 \%$ of the total fault area following Somerville et al. (1999). The effective stress drop for each asperity was selected according to Table 4. Average rise time $D_{a} / V_{\text {eff }}$ was estimated by the scaling relationship of Somerville et al. (1999) and reevaluated for the shallow asperity to have 2 times longer rise time than the deep asperities according to the results of Fig. 7 and Table 4. Velocity structure was assumed as in Table 5. Rupture velocities $V_{R}$ 
(a)

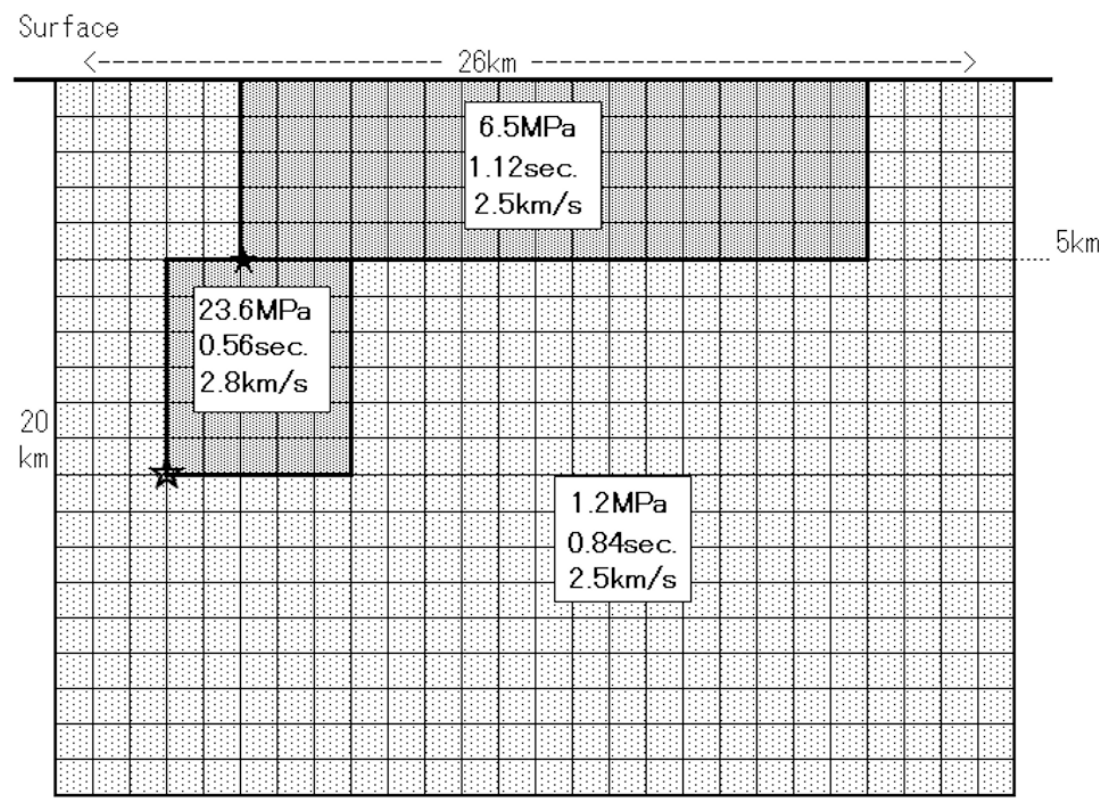

(b)

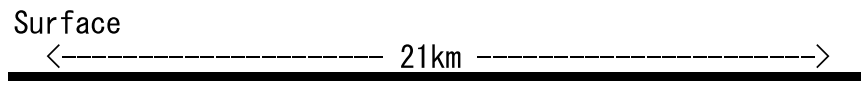

3

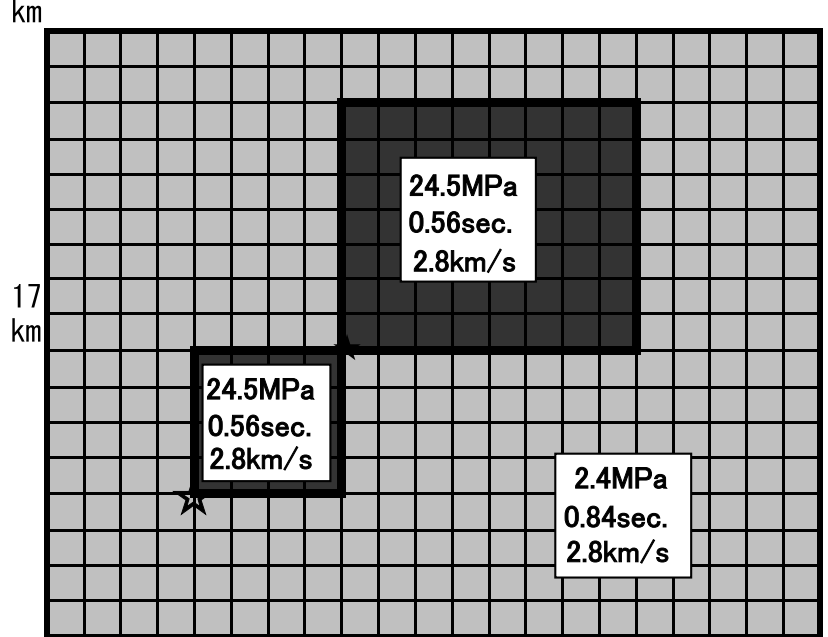

Fig. 8. Standard characteristic slip models for (a) surface rupture fault and (b) buried rupture fault; $M_{W}=6.5$ in both cases. The largest shallow asperity on surface rupture fault was set between 0 and $5 \mathrm{~km}$ depth; it has lower effective stress drop, longer rise time and slower rupture velocity than the deep asperity.

Table 5. Velocity and attenuation structures assumed for strong ground motion simulation. $Q$ values are explained as functions of frequency $f$.

\begin{tabular}{|c|c|c|c|c|c|}
\hline depth $(\mathrm{km})$ & $V p(\mathrm{~km} / \mathrm{s})$ & $V s(\mathrm{~km} / \mathrm{s})$ & $\rho\left(\mathrm{tf} / \mathrm{m}^{3}\right)$ & $Q s$ & $Q p$ \\
\hline $0.0 \sim 3.0$ & 5.4 & 3.2 & 2.7 & $130 \times f^{0.77}$ & $260 \times f^{0.77}$ \\
\hline $3.0 \sim$ & 6 & 3.5 & 2.9 & $130 \times f^{0.77}$ & $260 \times f^{0.77}$ \\
\hline
\end{tabular}

were set at $80 \%$ of the shear wave velocity $V_{S}$. Locations of the rupture starting points, asperities, and sites were almost the same for the surface and for the buried rupture earthquakes.

To avoid generation of surface fault rupture, following to the results of dynamic simulation of Dalguer and Irikura (2002) and Dalguer et al. (2003), the top depth of the largest asperity of the buried fault was set to $5 \mathrm{~km}$. Dalguer and Irikura (2002) simulated the generation of tensile (opening) cracks (Fig. 9) due to dynamic strike slip rupture with fault 


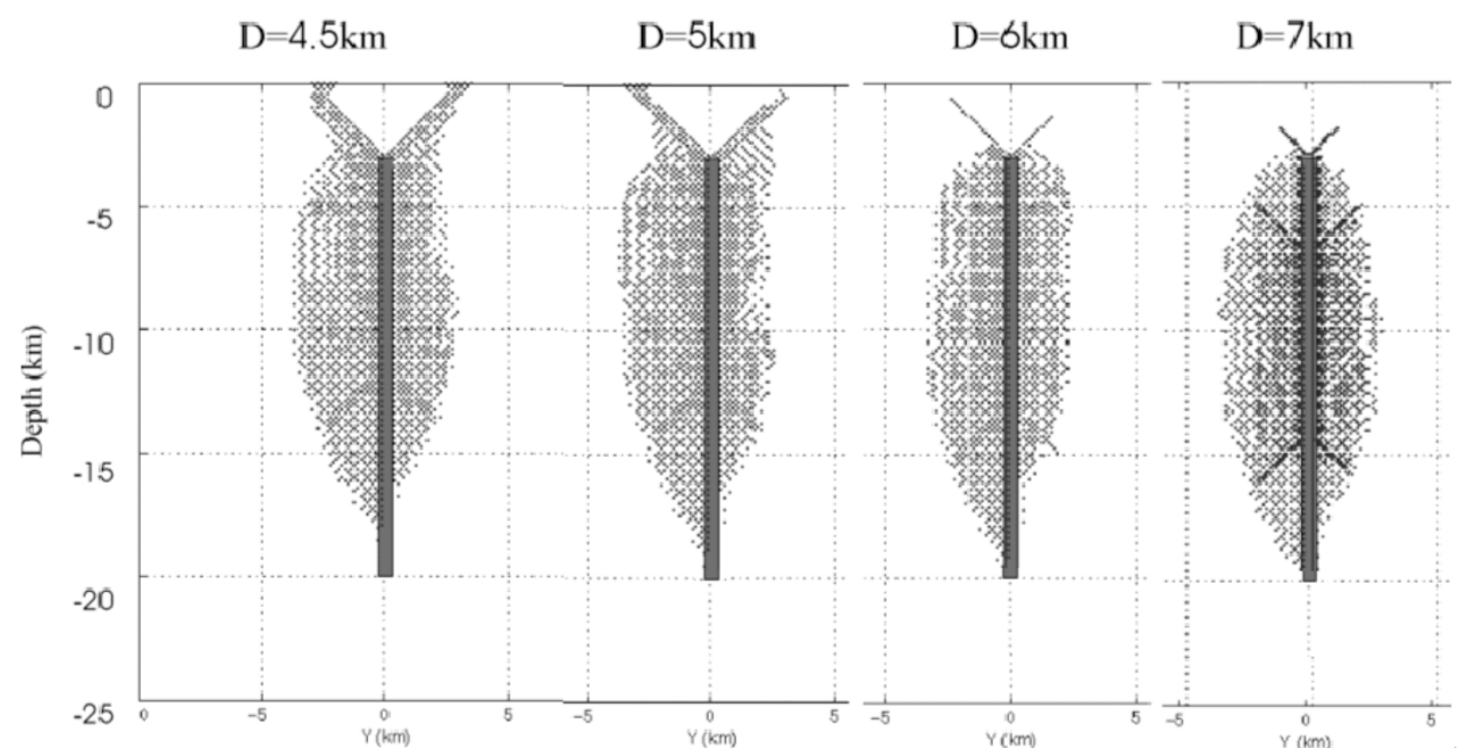

Fig. 9. Results of the dynamic simulation of generation of tensile cracks due to variation of top depth of asperity (Dalguer and Irikura, 2002, courtesy of Luis Angel Dalguer). Distributions of newly generated tensile cracks (diagonal thin lines) around the main fault (vertical thick line) are shown in the panels. When the top depth of the asperity becomes $5 \mathrm{~km}$, tensile cracks barely reach the surface.

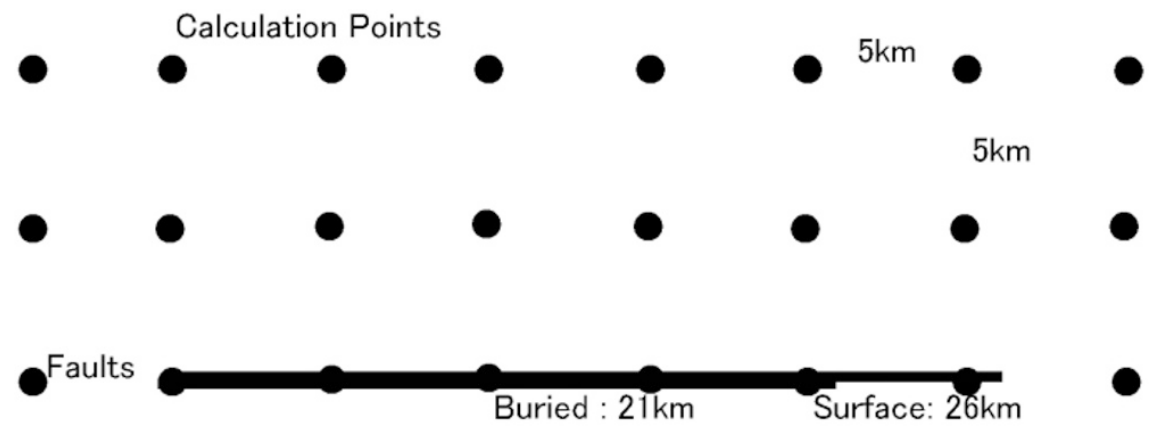

Fig. 10. Site locations for strong ground motion simulation.

Mwe 6.5

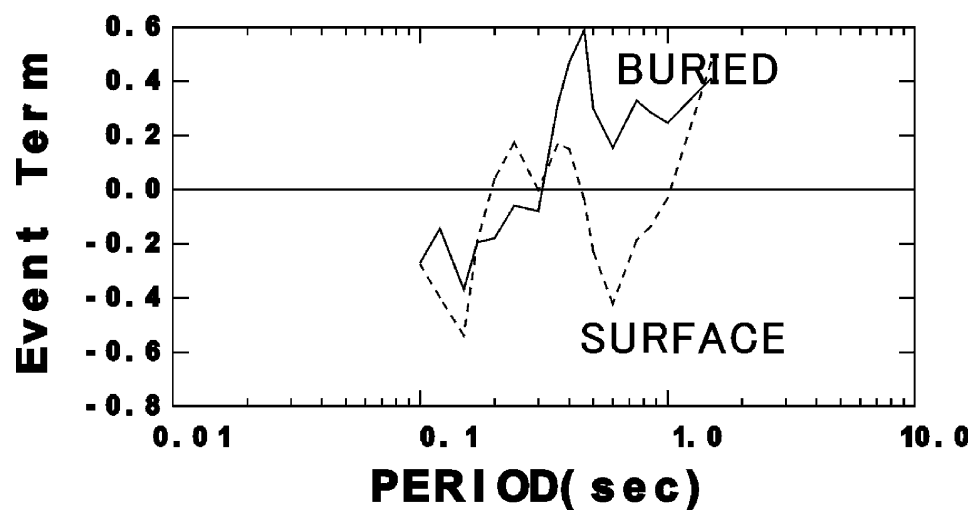

Fig. 11. Comparison of the simulated response spectra with the empirical spectral attenuation relationship of Abrahamson and Silva (1997). Compare this figure with Fig. 1.

parameter shown in Fig. 8. They found that if the asperity depth equals or exceeds $5 \mathrm{~km}$, the probability that the crack reaches the surface is very low.

We calculated ground motion response spectra for 21 sites on a $5 \times 5 \mathrm{~km}$ grid shown in Fig. 10 . Figure 11 com- pares the average simulated response spectrum with the empirical spectral attenuation relationship of Abrahamson and Silva (1997). The average event terms of the surface rupture model and the buried rupture model are indicated by the dash line and solid line respectively. The differences of 
the ground motions between the surface and buried rupture earthquakes in Fig. 11 have similar characteristics to those of the observed ground motions shown in Fig. 1. In the period range around 1 second, the ground motion due to buried rupture earthquake is larger than that from surface rupture earthquake, even though the surface rupture earthquake has a shallow asperity close to the surface and to the near-fault sites. Thus, we can conclude that the combined effect due to the differences in the (1) rupture area versus magnitude scaling, (2) depth of asperities, (3) their effective stress drop and slip velocity, is able to produce the observed difference in ground motions between the two types of earthquakes.

\section{Discussion and Conclusions}

Differences were identified in the ground motion and in the fault rupture characteristics between surface and buried rupture earthquakes. It was found and confirmed by the numerical simulations that in the period range around $1 \mathrm{sec}$, the ground motions from buried rupture earthquakes are significantly larger than the ground motions from surface rupture earthquakes.

At first glance this observation contradict the observation of large damage of buildings in surface rupture earthquakes such as the 1999 ChiChi, Taiwan, and 1999 Kocaeli, Turkey, earthquakes, in spite of them having lower ground motions than average (see Fig. 1, top panel). However, more detailed analysis in case of the 1999 ChiChi, Taiwan earthquake, shows that the damage was concentrated in a very narrow belt-like zone along fault, where the surface dislocation due to fault rupture could directly affect the buildings. This kind of phenomenon is usually reported through field surveys of earthquake damage, e.g. the 1990 Philippine earthquake, the 1995 Kobe, Japan, earthquake, and the 1999 Kocaeli, Turkey, earthquake. This suggests that the buildings were damaged mainly by the effects of surface dislocation, not by the strong ground motion.

The result derived here is important for evaluating the near-field ground motion for both surface rupture and buried rupture earthquakes. It is desirable to perform additional numerical verification of these observations using dynamic source simulations with realistic parameters.

The main results of the study are as follows.

1) Ground motion generated by buried rupture earthquakes in the period range around 1 second is larger than the ground motion generated by surface rupture events.

2) The large slips of surface rupture earthquakes are concentrated in the shallow portion of the fault.

3) The total rupture area of buried rupture earthquakes is smaller than that of surface rupture earthquakes. The effective stress drop of buried rupture earthquakes is larger than that of surface rupture earthquakes.

4) Deep asperities have larger effective stress drops and higher slip velocities than shallow asperities.

5) Ground motions simulated using fault rupture models constructed according to the above results demonstrate spectral differences between surface and buried rupture earthquakes similar to observed differences.

Acknowledgments. We would like to thank Ken Miyakoshi, Tomotaka Iwata, Haruko Sekiguchi, and David J. Wald for their works on waveform inversion. Without their efforts, we could not complete this study. Anatoly Petukhin kindly proofread the manuscript and made technical corrections. We also thank associate editor and reviewers for suggestions that improved this paper.

\section{References}

Abrahamson, N. A. and W. J. Silva, Empirical response spectral attenuation relations for shallow crustal earthquake, Seism. Res. Lett., 68, 94-127, 1997.

Boore, D., Stochastic simulation of high-frequency ground motions based on seismological models of the radiation spectra, Bull. Seism. Soc. Am., 73, 1865-1894, 1983.

Dalguer, L. A. and K. Irikura, Generation of tensile cracks during a 3D dynamic shear rupture propagation, Japan Earth and Planetary Science Joint Meeting, S042-P017 (CD-ROM), 2002.

Dalguer, L. A., K. Irikura, and J. D. Riera, Simulation of tensile crack generation by three-dimensional dynamic shear rupture propagation during an earthquake, J. Geophys. Res., 108(B3), 2144 doi:10.1029/2001JB001738, 2003.

Eshelby, J. D., The determination of the elastic field of and ellipsoidal inclusion, and related problems, Proc. Roy. Soc., A241, 376-396, 1957.

Hartzell, S. H. and T. H. Heaton, Inversion of strong ground motion and teleseismic waveform data for the fault rupture history of the 1979 Imperial Valley, California, earthquake, Bull. Seism. Soc. Am., 73, 1,553-1,583, 1983.

Irikura, K., H. Miyake, T. Iwata, K. Kamae, T. Kagawa, and K. Miyakoshi, A recipe of strong motion prediction for scenario earthquake, AGU Fall Meeting, S31C-01, 2001

Iwata, T., H. Sekiguchi, and A. Pitarka, Source and site effects on strong ground motions in near-source area during the 1999 Chi-Chi, Taiwan, earthquake, AGU Fall Meeting, S72-P05, 2000.

Kamae, K. and K. Irikura, Prediction of site-specific strong ground motion using semi-empirical methods, 10WCEE, 801-806, 1992.

Miyakoshi, K., T. Kagawa, H. Sekiguchi, T. Iwata, and K. Irikura, Source characterization of inland earthquakes in Japan using source inversion results, 12WCEE, 1850, CD-ROM, 2000.

Sekiguchi, H. and T. Iwata, Source process inversion and near-source ground motion simulation of the 2000 Tottoriken-Seibu, Japan, earthquake (MW6.8), AGU fall meeting, S42C-0654, 2001.

Sekiguchi, H. and T. Iwata, Rupture process of the 1999 Kocaeli, Turkey earthquake estimated from strong-motion waveforms, Bull. Seism. Soc. Am., 92, 300-311, 2002.

Shimazaki, K., Small and large earthquake: the effects of thickness of seismogenic layer and the free surface, in Earthquake Source Mechanics, AGU Monograph, 37 (Maurice Ewing Ser. 6), edited by S. Das, J. Boaghtwright, and C. H. Sholz, pp. 209-216, 1986.

Somerville, P. G., Magnitude scaling of the near fault rupture directivity pulse, Phys. Earth Planet. Int., 137, 201-212, 2003.

Somerville, P. G., K. Irikura, R. Graves, S. Sawada, D. Wald, N. Abrahamson, Y. Iwasaki, T. Kagawa, N. Smith, and A. Kowada, Characterizing earthquake slip models for the prediction of strong ground motion, Seism Res. Lett., 70, 59-80, 1999.

Wald, D. J. and T. H. Heaton, Spatial and temporal distribution of slip of the 1992 Landers, California earthquake, Bull. Seism. Soc. Am., 84, 668-691, 1994.

Watanabe, M., T. Sato, and K. Dan, Scaling relations of fault parameters for inland earthquakes, 10th Jpn. Earthq. Eng. Symp., 583-588, 1998.

Wells, D. L. and K. J. Coppersmith, New empirical relationships among magnitude, rupture length, rupture width, rupture area, and surface displacement, Bull. Seism. Soc. Am., 84, 974-1002, 1994.

Yoshida, S. and K. Koketsu, Simultaneous inversion of waveform and geodetic data for the rupture process of the 1984 Naganoken-Seibu, Japan, earthquake, Geophys. J. Int., 103, 355-362, 1990.

T. Kagawa (e-mail: kagawa@geor.or.jp), K. Irikura, and P. G. Somerville 